\title{
Accelerated life testing of frozen green beans (Phaseolus vulgaris, L.) quality loss kinetics: colour and starch
}

\author{
R.C. Martins, I.C. Lopes, C.L.M. Silva * \\ Escola Superior de Biotecnologia, Universidade Católica Portuguesa, Rua Dr. António, Bernardino de Almeida, 4200-072 Porto, Portugal
}

Keywords: Accelerated life testing; Kinetics; Frozen green beans; Colour; Starch

\begin{abstract}
This study uses the information derived from a computational research for the design of accelerated life testing (ALT) to implement experimentally the step stress methodology for the quantification of frozen green beans (Phaseolus vulgaris, L.) colour and starch degradation kinetics. Colour loss and starch degradation were successfully modelled, respectively, by a first-order reversible and apparent first-order kinetics, under dynamic temperature fluctuations.

Results show that the step stress produces models with lower regression standard errors than the conventional isothermal methodology, increasing the accuracy of the estimated kinetic parameters. The ALT methodology, produces however, higher confidence intervals for the estimated kinetic parameters, than the isothermal methodology (e.g. colour $b$-coordinate by the: (i) isothermal methodology: $k_{-15}{ }^{\circ} \mathrm{C}=22.189 \pm 0.349 \mathrm{day}^{-1} \times 10^{-3}$; and (ii) ALT methodology: $k_{-15}{ }^{\circ} \mathrm{C}=22.189 \pm 0.349 \mathrm{day}^{-1} \times 10^{-3}$ ).

Furthermore, as expected, higher Arrhenius activation energies $\left(E_{\mathrm{a}}\right)$ were estimated by the ALT step-stress methodology, than by the isothermal methodology (e.g. Hunter total colour difference $\left(\mathrm{TCD}_{\mathrm{H}}\right)$ : (i) isothermal methodology: $E_{\mathrm{a}}=106.272 \pm 18.67 \mathrm{~kJ} \mathrm{~mol}^{-1}$; and (ii) ALT methodology: $E_{\mathrm{a}}=140.344 \pm 18.670 \mathrm{~kJ} \mathrm{~mol}^{-1}$ ).

Accelerated tests are valuable tools, that can aid the study of quality losses in frozen foods. Although ALT tests increase the complexity of data analysis, they produce satisfactory results, when applied to frozen green beans kinetics of starch and colour losses.
\end{abstract}

\section{Introduction}

The quality loss of frozen vegetables is characterised by very slow kinetic rates and, therefore, the time involved in isothermal kinetic studies of frozen foods is very long, where data has to be recorded over a minimum period of 6-12 months. The risk of failure is very high, and special care has to be taken to maintain the set up temperature during the experimental period.
Accelerated life testing (ALT) techniques have been used to decrease the experimental time of long lasting events. ALT were firstly developed for reliability studies of mechanical failure of engine parts, hardware failure, control failure of nuclear reactors, and proved also to be a very effective tool applied to product development (Høyland \& Rausand, 1994). However, its application to frozen foods has been limited.

Most of the accelerated tests developed for the food industry, have been addressed directly to shelf-life estimation, and not applied to kinetics determinations (Labuza \& Schimdl, 1985). The first accelerated shelf-life tests (ASLT) exposed foods to overstress conditions (e.g. higher temperatures, lower $\mathrm{pH}$ and high 


\section{Nomenclature}

$a \quad$ Hunter $a$ co-ordinate, degree of red/green

$a_{\mathrm{w}} \quad$ water activity

$b \quad$ Hunter $b$ co-ordinate, degree of blue/yellow

$C \quad$ concentration

$E_{\mathrm{a}} \quad$ Arrhenius activation energy, $\mathrm{J} \mathrm{mol}^{-1}$

$k \quad$ kinetic rate, day $^{-1}$

$L \quad$ Hunter $L$ co-ordinate, degree of lightness

$R \quad$ universal gas constant, $\mathrm{J} \mathrm{mol}^{-1} \mathrm{~K}^{-1}$

$T \quad$ temperature, $K$ $t \quad$ time, days

TCD total colour difference

Subscripts

0 refers to initial condition

eq refers to equilibrium quality content

$\mathrm{H}$ refers to the Hunter colour space

ref refers to a reference temperature $\left.a_{\mathrm{w}}\right)$ to accelerate the shelf-life decay. These early ASLT methods used the two step isothermal approach, where isothermal storage experiments are made at the higher stressor variable levels, such as temperature, to extrapolate shelf-life at lower temperatures (Labuza \& Schimdl, 1985; Ragnarsson \& Labuza, 1977; Waletzko \& Labuza, 1976). However, extrapolation involves uncertainty risk on the predicted data, as regression confidence bands expand as the distance from the average temperature increases, especially if the tested range is narrow (Bates \& Watts, 1988; Box, Hunter, \& Hunter, 1978; Neter, Kutner, Nachtsheine, \& Wasserman, 1996).

Some non-isothermal methodologies try to avoid extrapolation, by using for example a linear increase in temperature, to cover the needed temperature range in study and estimate the kinetic parameters (Brandão \& Oliveira, 1997; Frias, 1998; Nunes, Rhim, \& Swartzel, 1991; Moreira, Oliveira, Silva, \& Oliveira, 1993; Rhim, Nunes, Jones, \& Swartzel, 1989a, 1989b). These methodologies have been used for kinetic studies, but not in the field of frozen foods. However, a deterministic linear temperature increment is very difficult to maintain inside a refrigerator, because of temperature fluctuations, due to the on/off compressor cycles.

In every kinetic study a preliminary study has to be done to determine the kinetic law and its relationship with temperature. The direct use of the ALT methodologies should be avoided, because results are treated on empirical basis. For this purpose, the quality degradation pathway should be studied previously, in order to identify a mechanistic behaviour, otherwise quality losses predictions may fail under unexpected scenarios.

During frozen storage, low protein foods exhibit a pH decrease (e.g. milk, green beans) (Ehart, 1970; Fennema, Powrie, \& Marth, 1973). The pH decrease increases the acid catalysed reactions rate (Rafael, 1992), such as starch hydrolysis and chlorophyll's pheophytisation. As starch is hydrolised, the glucose content increases, and green beans become sweeter with storage time. The glucose content increase can be monitored by a reduced sugars determination. Chlorophyll's phyophy- tisation is the most important cause of colour loss, from a vivid green to an olive brown colour.

The colour and starch degradation mechanisms in frozen green beans (Phaseolus vulgaris, L.) were previously studied, and their kinetics were estimated by an isothermal experimental design (Martins \& Silva, 2002, 2003).

Starch hydrolysis was described by an apparent first order reaction kinetics with Arrhenius behaviour with temperature under isothermal conditions:

$C=C_{0} \cdot \exp \left(-k_{\text {ref }} \cdot \exp \left[-\frac{E_{\mathrm{a}}}{R} \cdot\left(\frac{1}{T}-\frac{1}{T_{\text {ref }}}\right)\right] \cdot t\right)$

where $C$ is the starch concentration at time $t, C_{0}$ the initial concentration, $k_{\text {ref }}$ the kinetic rate at the absolute reference temperature, $T_{\text {ref }}, T$ the absolute temperature, $R$ the universal gas constant and $E_{\mathrm{a}}$ the Arrhenius activation energy.

Colour was well described by a first order reversible reaction kinetics, with Arrhenius behaviour with temperature under isothermal conditions as well:

$\frac{C-C_{\text {eq }}}{C_{0}-C_{\text {eq }}}=\exp \left(-k_{\text {ref }} \cdot \exp \left[-\frac{E_{\text {a }}}{R} \cdot\left(\frac{1}{T}-\frac{1}{T_{\text {ref }}}\right)\right] \cdot t\right)$

where $C$ is the $a$ Hunter colour parameter $(a, b$ and $\left.\mathrm{TCD}_{\mathrm{H}}\right)$ at time $t, C_{0}$ the initial colour value, and $C_{\mathrm{eq}}$ the colour value at infinite storage time, when all chlorophyll is converted into pheophytin. This model assumes that the initial and final colour co-ordinates are not dependent on the storage temperature, and vary only due to pheophytisation.

Two main difficulties exist in the design of frozen foods quality loss experiments: (i) long experimental times and (ii) temperature fluctuations inside a refrigerator. Thermal fluctuations inside freezers accelerate quality losses and decrease the accuracy of the estimated kinetic parameters, if a constant temperature is assumed during regression analysis.

The effect of thermal fluctuations was studied during computational design of accelerated life tests (Martins, 2004). This research lead to the conclusion that by 
taking into account the time-temperature spectrum inside a refrigerator, it is possible to increase the accuracy of the estimated kinetic model (Martins, 2004). As time, temperature and quality losses are evaluated at regular time intervals, the dynamic ALT tests overcome the problem of temperature fluctuations inside the refrigerator.

ALT tests have been applied in the frozen food industry in a very practical approach. The methodology adopted was to subject frozen foods to a number of freeze-thaw cycles, until quality degradation was evident. Thereafter, shelf life was 'extrapolated' to normal storage and distribution conditions, on a empirical basis (Reid, Kotte, \& Kilmartin, 1999). Although this test is preferred, due to practical reasons, it supposes a subjective interpretation of product's shelf life by the product developer. Furthermore, as degradation kinetics, storage and distribution conditions are not taken into account, this technique is therefore limited.

As the ALT tests were previously tested for accuracy and precision by computer simulation, the objectives of this research, focus on:

(i) Demonstrate the experimental applicability of the simulated ALT methodology using frozen green beans;

(ii) Compare the ALT method kinetic estimates with the general isothermal methodology;

(iii) Validate experimentally the use of ALT methodologies to estimate kinetic parameters of frozen foods quality losses.

\section{Materials and methods}

\section{Sample preparation}

Green beans (Phaseolus vulgaris, L.) were obtained from Porto local city market-Portugal, one day after harvesting. They were firstly sorted, washed and blanched in water for $2 \mathrm{~min}$ at $100{ }^{\circ} \mathrm{C}$. After blanching, green beans were left to cool and dry, and then frozen in a blast freezer, Armfield FT 36. Samples were frozen at an average air temperature of $-40{ }^{\circ} \mathrm{C}$, until the temperature of $-35{ }^{\circ} \mathrm{C}$ was recorded with a thermocouple placed in the centre of a green bean test sample. Approximately $500 \mathrm{~g}$ of frozen green beans were immediately put into polyethylene bags $(35 \mathrm{~cm} \times 22 \mathrm{~cm})$ and heat sealed. Packed frozen green beans were stored in a laboratory refrigerator (Fitotherm, model S550 BT) at the temperature of $-30 \pm 1{ }^{\circ} \mathrm{C}$.

\section{Accelerated life testing (ALT)}

The increase step stress method and the linear increase stress method, were tested by computer simula- tion, leading to the conclusion that these methods were good methodologies to estimate kinetic parameters for frozen stored green beans (Martins, 2004). However, the increase step stress method is easier to implement, because there is no need to add a special temperature control to the refrigerator. Therefore, the increase step stress was chosen as the most straight forward ALT methodology to be experimentally implemented.

In this type of dynamic test the storage temperature (stressor variable) is increased gradually by steps (Høyland \& Rausand, 1994), until all green beans reach the final quality content (zero for first-order kinetics, or final residual value, $C_{\mathrm{eq}}$ for fractional conversion kinetics). The design expects an average of $25 \%$ of quality degradation for each stress level. Thus, the green bean sample is exposed for 15, 7, 6 and 5 consecutive days at the average thermostat temperature of -30 , $-20,-10$ and $-5{ }^{\circ} \mathrm{C}$, respectively.

Two refrigerators were used to achieve the temperature steps. Green bean samples were put on trays, inside refrigerator number one at the fist temperature level, $-30{ }^{\circ} \mathrm{C}$. Meanwhile, the second refrigerator is set to the second temperature level, $-20{ }^{\circ} \mathrm{C}$. After the first 15 days, the remaining green beans are changed from refrigerator number one to the second refrigerator for the next 7 days at $-20{ }^{\circ} \mathrm{C}$. During this period, it is possible to set up the temperature level of the first refrigerator to $-10{ }^{\circ} \mathrm{C}$, in order to get it ready to receive the green beans trays. The design continues, using this cycle, until the quality change rate is approximately zero.

The quality losses and temperature spectrum have to be continuously evaluated along the experiment. A green bean specimen is, therefore, used to obtain the time-temperature spectrum. A Cu/Ni thermocouple (type $\mathrm{K}$ ) is inserted into the green bean, placed at the thermal centre, and connected to a temperature recorder, Grant Instruments 1000 Series Squirrel Metter/Logger. Thereafter, the green bean is placed on the centre of the tray, and the temperature is recorded every minute.

Quality losses evaluation of green beans, colour and starch, was carried out only during the day. Ten samples were obtained along a $10 \mathrm{~h}$ period, at a sampling rate of one per hour. Thereafter, sampling was interrupted for $14 \mathrm{~h}$ overnight, and this scheme continued in the following day. Measurements were made with five replicates for each storage sample.

\section{Colour measurement}

The first measurements were made immediately before and after freezing. The Hunter Lab co-ordinates were measured by a tristimulus colorimeter (model CR300, Minolta Corporation, Japan). The colorimeter was calibrated with a standard white tile $(Y=95.3$, $x=0.3133, y=0.3197)$. Green beans were thawed and cut into small rectangles, and thereafter, placed on the 
platform of the colorimeter. The Hunter co-ordinates $L$, $a$ and $b$ were recorded and the Hunter total colour difference $\left(\mathrm{TCD}_{\mathrm{H}}\right)$ was calculated:

$\operatorname{TCD}_{\mathrm{H}}=\sqrt{\left(L-L_{0}\right)^{2}+\left(a-a_{0}\right)^{2}+\left(b-b_{0}\right)^{2}}$

where $L, a$ and $b$ are the Hunter co-ordinates measured at time $t$, and $L_{0}, a_{0}$ and $b_{0}$ are the corresponding initial values.

Starch

About $30 \mathrm{~g}$ of sample is required for the determination. After blending the vegetables, free sugars are completely removed by repeated extractions with aqueous ethanol. Then the starch residue is solubilised in alkali and hydrolysed by glucoamylase to glucose, and the glucose content is determined by the Luff-Schoorl method (NP-1420, 1987). The vegetable extract, previously clarified with Carrez I solution (Potassium Hexacyanoferrate II $150 \mathrm{~g} / \mathrm{l}$ ), is heated to boiling with Luff-Schoorl solution. The directly reducing sugars are thereby oxidised and the divalent copper of the Luff-Schoorl solution is reduced to monovalent copper. This is precipitated as copper (I) oxide and is measured by indirect titration with sodium thiosulphate in the presence of sulphuric acid. Sugar content is then determined by interpolation in a table, after subtracting the blank assay to the volume of sodium thiosulphate of the titration.

Data analysis

Non-linear regression analysis for model fitting was performed on all data. The non-isothermal first-order and reversible first-order (Eqs. (4) and (5), respectively), kinetic parameters were obtained, by maximising the likelihood function and solving the normal equations of

$$
C=C_{0} \cdot \exp \left(-k_{\text {ref }} \cdot \int_{0}^{t} \exp \left[-\frac{E_{\mathrm{a}}}{R} \cdot\left(\frac{1}{T}-\frac{1}{T_{\text {ref }}}\right)\right] \cdot \mathrm{d} t\right)
$$

$$
\frac{C-C_{\mathrm{eq}}}{C_{0}-C_{\mathrm{eq}}}=\exp \left(-k_{\mathrm{ref}} \cdot \int_{0}^{t} \exp \left[-\frac{E_{\mathrm{a}}}{R} \cdot\left(\frac{1}{T}-\frac{1}{T_{\mathrm{ref}}}\right)\right] \cdot \mathrm{d} t\right)
$$

which are non-isothermal integrations of Eqs. (1) and (2), respectively.

A computer program was developed with the $\mathrm{C}++$ language, using the BLITZ++ Library (Veldhuizen, 2001), with the Gauss-Newton optimisation algorithm to solve the normal equations and determine the parameters estimates. The estimated parameter's variance was obtained by the variance-covariance matrix of the regression coefficients and the model standard deviation was estimated by the mean standard error (Bates \& Watts, 1988; Neter et al., 1996).

The studentised effect $\left(\beta_{i} / s\left\{\beta_{i}\right\}\right)$ of each kinetic parameter was computed to define the statistical importance at a $5 \%$ confidence level (double sided $T$-test). The semi studentised residuals were examined for outlayers, randomness and tested for normality (Box et al., 1978), to assess the quality of the fitted kinetic models. The models statistical validity was also accessed by the lack of fit test.

\section{Results and discussion}

Starch and colour (parameters $a, b$ and $\mathrm{TCD}_{\mathrm{H}}$ ) regression estimates, obtained with the proposed ALT methodology, are presented in Table 1. The corresponding kinetic parameters, obtained by the isothermal method and previously published (Martins \& Silva, 2002, 2003).

Table 1

\begin{tabular}{|c|c|c|c|c|}
\hline \multirow[t]{2}{*}{ Kinetic parameter } & \multirow[t]{2}{*}{ Starch $(\mathrm{g} / 100 \mathrm{~g})$} & \multicolumn{3}{|l|}{ Colour parameter } \\
\hline & & $a$ & $b$ & $\mathrm{TCD}_{\mathrm{H}}$ \\
\hline$C_{0}{ }^{\mathrm{a}}$ & $8.221 \pm 0.119$ & $-11.931 \pm 0.072$ & $13.099 \pm 0.117$ & $3.745 \pm 0.095$ \\
\hline$C_{0}^{\mathrm{b}}$ & $7.951 \pm 0.487$ & $-11.876 \pm 0.144$ & $12.774 \pm 0.179$ & $3.556 \pm 0.149$ \\
\hline$C_{\mathrm{eq}}{ }^{\mathrm{a}}$ & - & $-6.329 \pm 0.083$ & $10.101 \pm 0.072$ & $7.486 \pm 0.117$ \\
\hline$C_{\mathrm{eq}}^{\mathrm{q}}$ & - & $-6.253 \pm 0.543$ & $10.174 \pm 1.682$ & $7.385 \pm 0.112$ \\
\hline$k_{-15}{ }^{\circ} \mathrm{C} \times 10^{-3}\left(\mathrm{day}^{-1}\right)^{\mathrm{a}}$ & $98.96 \pm 0.77$ & $6.600 \pm 0.000$ & $22.189 \pm 0.349$ & $5.999 \pm 0.000$ \\
\hline$k_{-15{ }^{\circ} \mathrm{C}} \times 10^{-3}\left(\mathrm{day}^{-1}\right)^{\mathrm{b}}$ & $68.86 \pm 19.43$ & $1.759 \pm 0.468$ & $12.163 \pm 2.235$ & $135.976 \pm 15.981$ \\
\hline$E_{\mathrm{a}}\left(\mathrm{kJ} \mathrm{mol}^{-1}\right)^{\mathrm{a}}$ & $12.331 \pm 1.204$ & $103.053 \pm 0.072$ & $55.329 \pm 1.785$ & $106.272 \pm 1.049$ \\
\hline$E_{\mathrm{a}}\left(\mathrm{kJ} \mathrm{mol}^{-1}\right)^{\mathrm{b}}$ & $12.333 \pm 3.256$ & $111.973 \pm 9.966$ & $75.292 \pm 29.942$ & $140.344 \pm 18.670$ \\
\hline $\mathrm{SE}^{\mathrm{a}}$ & 0.915 & 1.389 & 1.557 & 1.872 \\
\hline $\mathrm{SE}^{\mathrm{b}}$ & $1.213 \times 10^{-3}$ & 1.513 & 1.559 & 1.502 \\
\hline Corr. coeff. ${ }^{\mathrm{a}}$ & 0.9775 & 0.8388 & 0.6871 & 0.6145 \\
\hline Corr. coeff. $^{\mathrm{b}}$ & 0.8941 & 0.9315 & 0.8562 & 0.8836 \\
\hline
\end{tabular}

Quality loss kinetic parameters of frozen green beans obtained by isothermal and ALT methodologies

${ }^{a}$ Data obtained by isothermal methods (Martins and Silva, 2002, 2003).

${ }^{\mathrm{b}}$ Data obtained by the ALT methodology. 
(a)

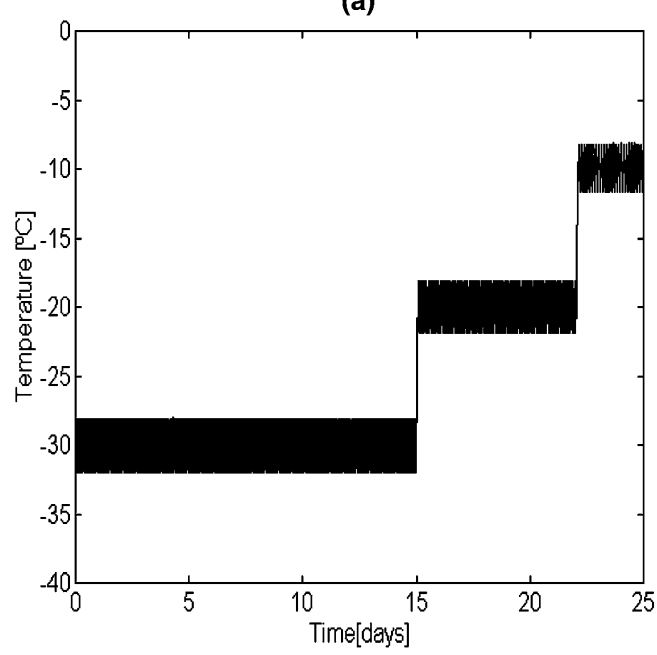

(c)

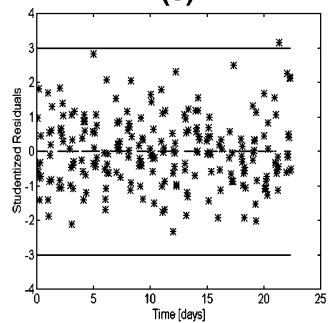

(e)

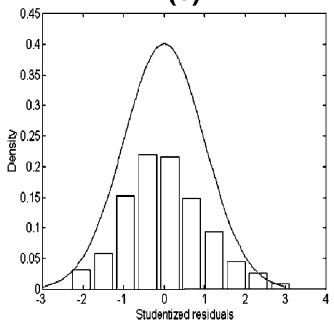

(b)

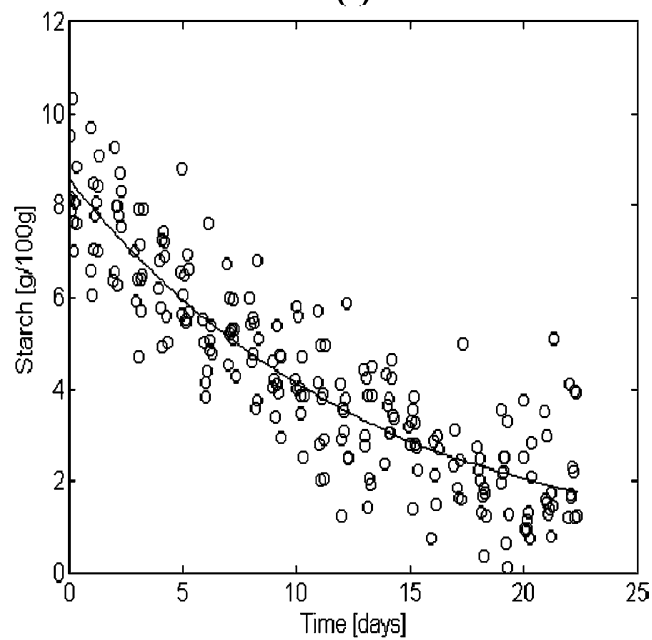

(d)

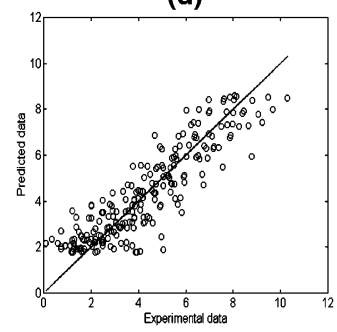

(f)

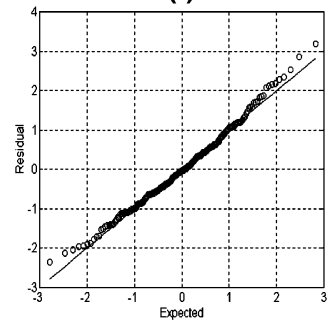

Fig. 1. Starch ALT regression analysis: (a) time-temperature spectrum; (b) starch content evolution; (c) regression semi-studentised residuals; (d) predicted vs. experimental plot of starch concentration; (e) density plot of semi-studentised residuals, and (f) normal probability plot of residuals.

Starch

The ALT test results for the starch content are presented in Fig. 1. The starch content decreased quite rapidly, even at the lowest temperature of $-30{ }^{\circ} \mathrm{C}$. The starch degradation was well described by an apparent first order reaction kinetics, with a good accuracy under the dynamic temperature conditions. Residuals show a random pattern and are near normality (see Fig. 1f). Starch hydrolysis is not a very temperature sensitive reaction $\left(E_{\mathrm{a}}=12.333 \pm 3.256 \mathrm{~kJ} \mathrm{~mol}^{-1}\right)$, but the Ahrrenius equation is required to describe the kinetic rate behaviour with storage temperature $\left(t\left\{E_{\mathrm{a}}\right\}>t_{\text {crit }}\right)$.

As starch determination involves the blending of different green beans, it was not possible to obtain a good estimate of the biological variability, and its influence on the regression estimates.
Colour

Colour degradation ALT test results are shown in Fig. 2, for the Hunter $a$-value. Similar results were obtained for the other colour parameters, $b$ and $\mathrm{TCD}_{\mathrm{H}}$. Colour differences between green beans were perceptible to the human eye even in the first measurement. The initial $\mathrm{TCD}_{\mathrm{H}}$ value is $3.556 \pm 0.149$ which is considered a very distinct difference perceptible to the human eye (DrLange, 1994).

Colour losses occurred at a significant fast rate for the higher temperature levels, -10 and $-5{ }^{\circ} \mathrm{C}$, and the degradation rate decreased very rapidly at the lower temperatures, -20 and $-30{ }^{\circ} \mathrm{C}$. This result was also obtained during isothermal experiments (Martins \& Silva, 2002). The probable explanation is the existence of metal ions, such as copper, which compete with hydrogen 
(a)

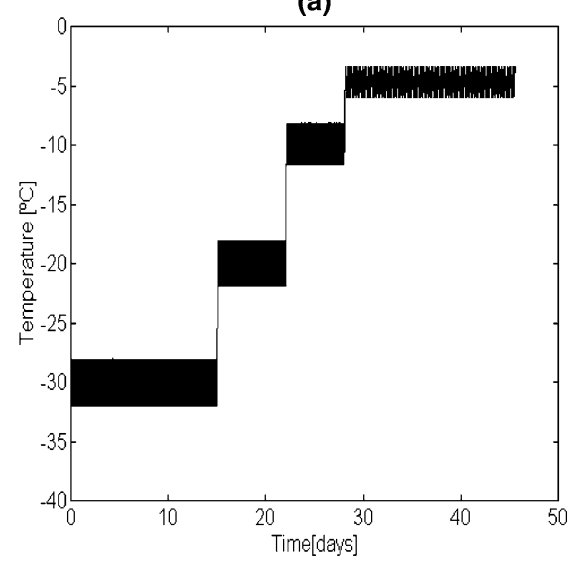

(c)

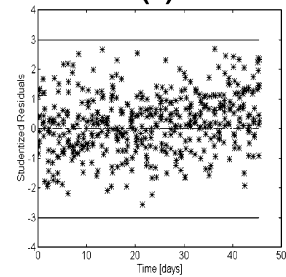

(e)

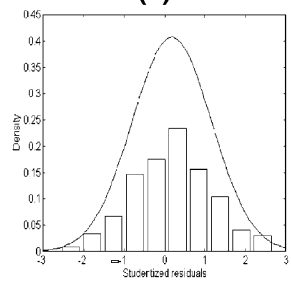

(b)

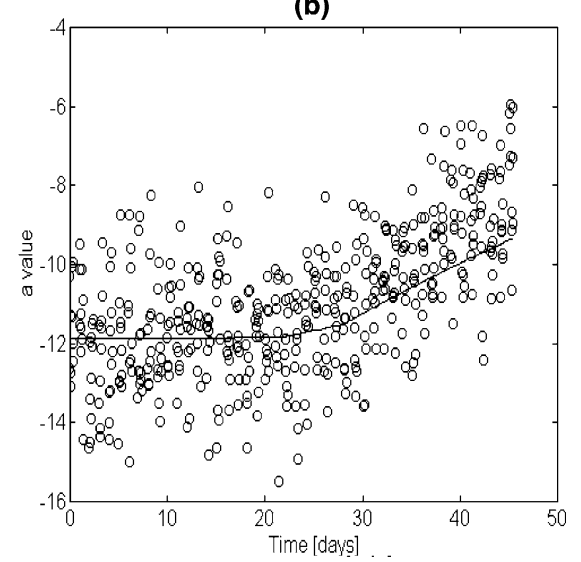

(d)

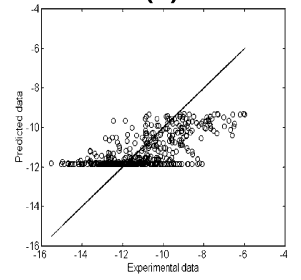

(f)

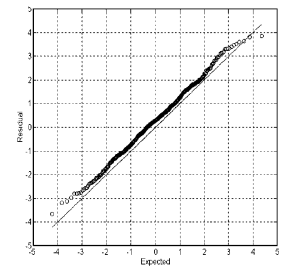

Fig. 2. Hunter $a$-value ALT regression analysis: (a) time-temperature spectrum; (b) $a$-value evolution; (c) regression semi-studentised residuals; (d) predicted vs experimental plot of $\mathrm{TCD}_{H}$; (e) density plot of semi-studentised residuals, and (f) normal probability plot of residuals.

in a parallel reaction, for the replacement of the centre chlorophyll magnesium, leading to colour stabilisation.

Colour stabilisation at the lower temperatures, and high degradation rate at the higher temperatures, reassures the great temperature sensitivity of colour loss kinetics to the storage temperature, under dynamic or isothermal conditions. Consequently, higher activation energy was estimated by the non-linear regression analysis (see Table 1).

Both the $a, b$ and $\mathrm{TCD}_{\mathrm{H}}$ values were successfully modelled by the first order reversible kinetics model under dynamic temperature conditions (Eq. (5)), passing the lack of fit test $(p>0.05)$. Residuals show a random pattern and are near normality (see Fig. 2f). Furthermore, the model parameters exhibit significant studentised effects (Table 1).

\section{Method discussion}

Results showed that the proposed ALT method was applicable to quantify kinetics of both starch and colour degradation of frozen green beans. The estimated kinetic parameters were similar to ones obtained under isothermal conditions (Martins \& Silva, 2002, 2003).

As expected from previous computer simulations (Martins, 2004), the studentised effect of the ALT regression parameters is less than the obtained from the isothermal experiments, and the regression standard error is of the same magnitude. However, it is not possible to determine experimentally if there is an increase in the accuracy of the estimated kinetic parameters, as expected by the computer simulations.

Although the ALT methodology reduces significantly the experimental time, this type of methodology presents some practical disadvantages: (i) it is very important that there is a correct synchronisation between timetemperature spectrum and the quality loss records; (ii) it requires a more sophisticated optimisation method than the isothermal methodologies; (iii) the kinetics estimation under dynamic conditions needs a significantly high level of degrees of freedom, compared to the isothermal methodology. Otherwise, kinetic parameter's 
variance may not be well estimated by the variancecovariance matrix, and collinearity between kinetic parameters will occur.

Furthermore, as the ALT test applied in this research was set to cover a broad band of quality parameters in terms of temperature sensitivity, it was possible to observe that the starch content was already near by zero values by the third day of test. The low temperature sensitivity of starch degradation makes this parameter losses very significant during the initial stages of the ALT test at $-30{ }^{\circ} \mathrm{C}$. Therefore, the presented ALT was well designed for colour degradation $\left(\mathrm{TCD}_{\mathrm{H}}\right)$, and not totally tunned for starch degradation, where less time should have been spent at lower temperatures.

In this last situation remedial measures have to be taken, such as reparametrisation and bootstrapping to get the parameter's estimated variance, in order to do interpret correctly the experimental results. The loss of parameter's precision is mainly attributed to the biological variability of foods, both for isothermal and dynamic kinetic studies. However, to produce statistically satisfactory fittings, the isothermal one step optimisation procedure needs significantly less degrees of freedom than the dynamic optimisation procedure. This result was also obtained during pharmaceutical studies, where results are very sensitive to experimental error, not being satisfactory at a $5 \%$ precision level (Labuza, 2004). However, for frozen foods, the inclusion of the time-temperature spectrum increases significantly the accuracy of the estimated regression models.

Isothermal methodologies need too long experimental times and heavy equipment, where at least three to five laboratory refrigerators, loaded with samples, are needed to cover the temperature range of interest. Moreover, the long experimental times increase the probability of failure, due to several causes, such as power loss, electrical and mechanical failure of refrigerator parts and human error. Furthermore, a good temperature control has to be implemented in each refrigerator, in order to consider the study as isothermal. For a summary of conclusions, Tables 2 and 3 present, respectively, isothermal and ALT methods advantages and disadvantages.

Table 2

Advantages and disadvantages of isothermal methods

\begin{tabular}{ll}
\hline Isothermal methods & \\
\hline Advantages & Disadvantages \\
\hline - Simple optimisation & $\bullet$ Long experimental times \\
procedures & $\bullet 3-5$ refrigerators are required \\
- Easier to identify the & $\bullet$ High failure probability \\
degradation mechanisms & $\bullet$ Need for good temperature \\
& control \\
\hline
\end{tabular}

Table 3

Advantages and disadvantages of ALT methodologies

\begin{tabular}{|c|c|}
\hline ALT methods & \\
\hline Advantages & Disadvantages \\
\hline $\begin{array}{l}\text { - Reduced experimental } \\
\text { time (8-10 times less than } \\
\text { isothermal methods) } \\
\text { - Increase in kinetic } \\
\text { parameter's accuracy }\end{array}$ & $\begin{array}{l}\text { - Need for a good optimisation } \\
\text { procedure } \\
\text { Remedial measures (such as } \\
\text { bootstrapping) have to be taken, } \\
\text { if parameters are not statistically } \\
\text { significant } \\
\text { - Correct synchronisation } \\
\text { between time-temperature } \\
\text { spectrum and quality loss } \\
\text { records }\end{array}$ \\
\hline
\end{tabular}

\section{Conclusions}

The step stress accelerated test proved to be a satisfactory methodology to determine the kinetic parameters of both starch and colour degradation in frozen green beans. The dynamic method exhibits not only good agreements between the observed and the predicted data, but also a good statistical and physical interpretation of the kinetic parameter estimates. Therefore, although there is an increase in the complexity of data analysis of ALT methodology, it has proved to be satisfactory when applied to frozen green beans starch and colour losses kinetics. The proposed methodology is an important step forward to the development of very useful accelerated methods to quantify frozen foods quality losses kinetics.

\section{Acknowledgment}

The author R.C. Martins gratefully acknowledges his PhD grant (PRAXIS XXI BD/18541/98) to the Fundação para a Ciência e Tecnologia (FCT), Portugal.

\section{References}

Bates, D., \& Watts, D. (1988). Non-linear regression analysis and it's applications. New York: John Wiley and Sons.

Box, G., Hunter, W., \& Hunter, J. (1978). Statistics for experimenters. New York: Wiley.

Brandão, T. R. S., \& Oliveira, F. A. R. (1997). The influence of the temperature increase rate on the accuracy of diffusion parameters estimate under non-isothermal conditions. International Journal of Food Science and Technology, 32, 63-72.

DrLange (1994). Colour review. DrLange application report no. 8e. DrLange, USA.

Ehart, M. S. (1970). Effect of storage and other variables on composition of frozen broccoli. Food Technology, 24, 1009-1032.

Fennema, O., Powrie, W., \& Marth, E. (1973). Low-temperature preservation of foods and living matter. New York: Marcel Dekker.

Frias, J. (1998). The development and application of product history indicators (PHI) for optimising product quality in drying process. 
Phd thesis, Escola Superior de Biotecnologia, Universidade Católica Portuguesa, Porto, Portugal.

Høyland, A., \& Rausand, M. (1994). System reliability theory: Models and statistical methods. New York: John Wiley and Sons.

Labuza, T. (2004). Available from: URL http://fscn1.fsci.umn.edu/ ted_labuza/tpl.html. Visited 08-04-2004.

Labuza, T. P., \& Schimdl, M. K. (1985). Accelerated shelf-life testing. Food Technology, 39, 57-64, 134.

Martins, R. C. (2004). Modelling temperature abuses to frozen foods and effects on quality. Phd thesis, Escola Superior de Biotecnologia, Universidade Católica Portuguesa, Porto, Portugal.

Martins, R. C., \& Silva, C. L. M. (2002). Modelling colour and chlorophyll's losses of frozen green beans (Phaseolus vulgaris, L.). International Journal of Refrigeration, 25, 987-995.

Martins, R. C., \& Silva, C. L. M. (2003). Kinetics of frozen stored green beans (Phaseolus vulgaris, L.) quality changes: texture, vitamin C, reduced sugars and starch. Journal of Food Science, 68(7), 2232-2237.

Moreira, L. A., Oliveira, F., Silva, T., \& Oliveira, J. (1993). Development of a non-isothermal method for determination of diffusional parameters. International Journal of Food Science and Technology, 28, 575-586.

Neter, J., Kutner, M., Nachtsheine, C., \& Wasserman, W. (1996). Applied linear statistical models (fourth ed.). Chicago: IRWIN.

NP-1420, N. P. (1987). Determinação dos açúcares totais, dos açúcares redutores e dos açúcares não redutores (sacarose), Técnica de Luff-
Schoorl, Processo corrente. Instituto Português da Qualidade (IPQ), Portugal.

Nunes, R. V., Rhim, J. W., \& Swartzel, K. R. (1991). Kinetic parameter evaluation with linearly increasing temperature profiles: integral methods. Journal of Food Science, 56, 1433-1437.

Rafael, S. (1992). Effect of storage time-food processing plants and marketing conditions on the quality of some frozen vegetables. Phd. thesis, University of Alexandria, Egypt.

Ragnarsson, J. O., \& Labuza, T. P. (1977). Accelerated shelf-life testing for rancidity in foods-a review. Food Chemistry, 2, 291-308.

Reid, D., Kotte, K., \& Kilmartin, P. (1999). A new method for accelerated shelf-life prediction for frozen foods. In Proceedings of the 20th International Congress of Refrigeration, IIR/IIF, Sydney, Australia.

Rhim, J. W., Nunes, R. V., Jones, V. A., \& Swartzel, K. R. (1989a). Determination of kinetic parameters using linearly increasing temperature. Journal of Food Science, 54, 446-450.

Rhim, J. W., Nunes, R. V., Jones, V. A., \& Swartzel, K. R. (1989b) Kinetics of colour change of grape juice generated using linearly increasing temperature. Journal of Food Science, 54, 776-777.

Veldhuizen, T. (2001). Blitz++ user's guide. Available from URL http://oonumerics.org/blitz/manual/BLITZ.ps. Visited 23-03-2004.

Waletzko, P., \& Labuza, T. P. (1976). Accelerated shelf-life testing of an intermediate moisture food in air and in oxygen-free atmosphere. Journal of Food Science, 41, 1338-1344. 